\title{
Internet no Setor Hoteleiro: uma abordagem sob a ótica dos empresários e dos turistas ${ }^{1}$
}

\section{Internet in the Hotel Sector: an approach from an entrepreneur and tourist point of view}

\author{
Nelsio Rodrigues de $\mathrm{Abreu}^{2}$ \\ Renata Francisco Baldanza ${ }^{3}$
}

\begin{abstract}
Resumo
O objetivo do presente artigo foi estudar a utilização da Internet como instrumento estratégico de marketing por empresários no setor hoteleiro da cidade de Maceió. Quanto à metodologia, trata-se de uma pesquisa exploratória-descritiva, cujos dados quantitativos foram coletados por meio de questionários estruturados aplicados aos empresários do setor hoteleiro e aos turistas, recebendo tratamento estatístico (descritivo e análise fatorial) sendo tabulados e processados por meio do software SPSS. Quanto aos empresários, levantou-se informações sobre uso ou não da internet como instrumento estratégico. Quanto aos turistas, foi utilizada a própria Internet através de um questionário on-line, visando alcançar somente pessoas que acessam a Internet para obter informações sobre turismo. Os resultados obtidos evidenciam que alguns empresários ainda não estão explorando adequadamente as potencialidades da Internet e que os turistas estão usando a Internet como mais um canal de compra de produtos/serviços turísticos.
\end{abstract}

Palavras-chave: marketing; internet; turismo; estratégias

\begin{abstract}
The objective of this paper was to study the utilization of the Internet as a strategic marketing instrument by hotel sector entrepreneurs in the city of Maceió. The methodology used was exploratory descriptive research, where quantitive data was collected using structured questionnaires given to hotel sector entrepreneurs and tourists, which received statistical treatment (descriptive and factorial analysis) and was tabulated and processed through SPSS software. Information was obtained from the entrepreneurs about the use or not of the internet as a strategic instrument. The Internet itself was used in the case of tourists using an on-line questionnaire with a view to only reaching those who access the internet to obtain information about tourism. The results which were obtained show that some entrepreneurs are still not adequately exploring the potentiality of the Internet and that tourists are using the Internet as one more channel for the purchase of tourist products/services.
\end{abstract}

Keywords: marketing; internet; tourism; strategies

\footnotetext{
${ }^{1}$ Artigo premiado como $3^{\circ}$ melhor trabalho do Seminário Internacional de Turismo - SIT 2008, em Curitiba, PR.

2 Doutor - Professor e Pesquisador da Faculdade de Economia, Administração Contabilidade - FEAC da Universidade Federal de Alagoas - UFAL. E-mail: nelsio@gmail.com

${ }^{3}$ Mestre - Professora e Pesquisadora do Instituto de Ciências, Humanas, Comunicação e Artes - ICHLA da Universidade Federal de Alagoas - UFAL. E-mail: renatafran@yahoo.com.br
} 


\section{Introdução}

A Internet tem apresentado potencialidades e taxas de crescimento extremamente dinâmicas. Esta evolução, associada ao seu baixo custo, à sua simplicidade e vantagens óbvias da utilização da Internet, levaram muitos empresários a acreditarem que o simples fato de estarem presentes na rede poderiam alavancar seus negócios. É razoável pensar que a presença na Internet poderá trazer benefícios imediatos e proporcionar a aquisição de know how, indispensável à obtenção de vantagens sobre à concorrência. Por estas razões, é que as empresas deveriam gastar algum tempo, antes de atuarem no ambiente virtual, definindo muito bem o que querem, visto que, é mais relevante conseguir chegar a um grupo selecionado de clientes (atingir o nicho de mercado da empresa), do que simplesmente marcar a presença na rede. Por outro lado, fazer marketing na Internet ainda envolve muitas incertezas, bem como um relativo insucesso de produtos de grande consumo na Internet, inseguranças nas operações e a violação da privacidade do usuário.

O objetivo deste artigo foi discutir sobre a utilização da Internet como estratégia de marketing por empresários no setor hoteleiro da cidade de Maceió-AL. Nesse sentido, buscou-se discutir as opções que a Internet potencializa as estratégias de marketing para as empresas do setor hoteleiro. Assim, a empresa deverá considerar e incorporar alguns princípios, sob pena de investir infrutiferamente.

Nesta perspectiva, foram abordados tópicos como: a comunicação/informação, serviços, aspectos de marketing/vendas, interfaces e segurança. Destarte, buscou-se analisar as potencialidades sobre o tema apontadas na literatura, tanto para aquelas empresas que atuam na Internet quanto aquelas que ainda não utilizam tal ferramenta e verificando também as expectativas dos turistas sobre os serviços prestados via internet pelas empresas do setor.

\section{Revisão de Literatura}

\subsection{Marketing na Internet}

Tanto a palavra marketing quanto Internet, coincidentemente, têm origem na cultura americana e utilizam-se de termos cunhados na língua inglesa, expressões advindas de uma rica e extensa nomenclatura de termos e jargões, resultando naqueles que se mantêm no original (alguns termos foram traduzidos e outros foram "aportuguesados"). Os consagrados autores Kotler e Armstrong (1993) definem marketing como o processo social e gerencial 
através do qual indivíduos e grupos obtêm aquilo de que necessitam e desejam por meio da criação e troca de produtos e valores. Os autores acrescentam que deve-se determinar as necessidades e desejos dos mercados-alvo e proporcionar satisfações desejadas de maneira mais efetiva e eficiente do que seus concorrentes.

O marketing não esteve sempre presente na bibliografia nem nas atividades organizacionais. A palavra marketing era inexistente até meados de 1909. O aparecimento e desenvolvimento do seu conceito, atividades e princípios ocorreu, sobretudo no século XX. Na primeira fase a centralização era na produção. Essa fase corresponde ao início da revolução industrial, quando a demanda era maior que a oferta. No segundo momento, solucionado o problema da produção, as empresas começaram a fabricar mais do que a demanda. Era necessário encontrar novos mercados e convencer os seus moradores de que era necessário consumir o produto. Nessa fase, o vendedor começa a ter papel fundamental no marketing, porém não havia concorrência. Com o tempo começaram a surgir empresas concorrentes, que apresentavam produtos semelhantes, praticamente pelo mesmo preço. Nessa fase ganhava quem conseguisse satisfazer o cliente; surge a fase de marketing.

Compreender e conhecer as potencialidades da Internet é um parâmetro para entender o que está acontecendo atualmente com o marketing. A Internet oferece um novo paradigma para organizar, recuperar e publicar informações em ambientes on-line. Assim, as empresas devem reavaliar seu posicionamento estratégico, levando em consideração a vantagem competitiva decorrente da utilização da Internet.

O reconhecimento da Internet é apontado como o quarto canal para a efetivação do comércio, sendo que os outros três são: o pessoal, o correio e o telefone. Este quarto canal abre uma série de oportunidades inexistentes anteriormente e que não significarão a eliminação dos canais antigos e muito menos dos negócios baseados nos modelos existentes. Diante do exposto, destacam-se duas vantagens de trabalhar com marketing na Internet: a primeira é o atendimento totalmente personalizado a um custo de atendimento de massa e, a segunda grande vantagem, mais imediata, é por exemplo a substituição dos catálogos e manuais. Fica muito mais completo, atual e barato para quem produz e não ocupa espaço de quem utiliza (ARZUAGA, 1999; CHENG et al. 2006).

Silva e Oliveira (1997) realizaram uma análise das ações de marketing das organizações nesse novo meio levando em consideração os quatro P's (produto, preço, praça e promoção) propostos por Kotler; os quatro de C's (cliente, custo, conveniência e comunicação) propostos 
por Schultz, Tannembaum e Lauterborn e a abordagem de Dufour que propõe o mix do cybermarketing (produto, preço, distribuição e comunicação). Como resultados, evidenciaram as seguintes ações de marketing nesse novo meio:

Como conseqüência da globalização, os produtos (bens e serviços) podem ser criados e produzidos em diferentes locais, cabendo às empresas o papel da busca pela expansão do conceito de produto, via Internet, através dos serviços de atendimento ao consumidor e de pós-vendas. O preço, que é uma decorrência da percepção do cliente, passa a ter seu foco sobre os meios de pagamento e as questões legais e de segurança nas transações, refletindo os custos de produção e distribuição na Rede. A praça ou distribuição expande-se para o espaço virtual da própria Rede, na busca pela distribuição de produtos on-line, em qualquer tempo e lugar. A promoção ou Comunicação é realizada na Web, incorporada como nova mídia, em seu caráter de interatividade. (SILVA; OLIVEIRA, 1997, p.6)

No entanto, o importante não é o número de P's ou C's, mas sim a forma que a empresa, tanto tradicional quanto virtual, esteja empenhada em satisfazer da melhor maneira possível seu cliente. E, quando se trata do setor de turismo, deve se ter uma percepção aguçada, pois lidase com a emoção do indivíduo, que muitas vezes está realizando o sonho de viajar. Isto é essencial, pois como comentado anteriormente, o marketing trata do conjunto de atividades voltadas para satisfação das necessidades e desejos dos consumidores. Destarte, o uso da Internet beneficiará os empresários que souberem atender as expectativas de seus consumidores.

Abreu (2006) reforça esta discussão com a abordagem colaborativa que a Internet permite, ou seja, os consumidores atualmente não ficam dependentes apenas das informações prestadas pelas empresas, mas eles podem interagir com outras pessoas através da rede e obter informações detalhadas dos produtos/serviços que anseiam adquirir, levando em consideração as experiências de outros usuários. $\mathrm{O}$ autor denomina esta nova abordagem de 'trocas de experiências vivenciadas', haja vista que não objetiva transacionar bens ou serviços, mas apenas trocar experiências sem objetivo de lucro.

\subsection{A relevância do turismo e o uso das novas tecnologias}

Alguns autores destacam a importância da história para a evolução do turismo. A princípio, o que seria do turismo sem a História, e, de certa forma, o que seria da história sem o turismo, nesse segundo aspecto de uma forma mais branda.

Tem-se observado não só no Brasil, mas no mundo todo, que a história tem dado uma contribuição primordial ao turismo (URRY, 1996; SWINGLEHURST, 2001). Atualmente, 
sabe-se que a indústria do turismo é uma das que mais têm se desenvolvido no mundo, gerando empregos e tornando-se a principal fonte de renda de muitos países.

Portanto, verifica-se que o planejamento é um ponto chave para transformar um atrativo em ponto turístico. Para tanto, torna-se importante o planejamento adequado, com profissionais qualificados, verificando-se todas as partes envolvidas. É no planejamento, que se aplicam as pesquisas necessárias para avaliar fatores como: o que pensam os moradores locais a respeito, com que recursos podem-se contar, o que o turista espera do local, entre outros. $\mathrm{O}$ planejamento é a busca minuciosa por detalhes que amanhã poderão ser problemas se não administrados desde o início.

Assim, sabe-se que as indústrias do turismo e da tecnologia da informação, são as que apresentam o maior, mais rápido e dinâmico crescimento no mundo. A atividade econômica resultante do setor viagens e turismo é uma importante fonte geradora de empregos e de renda. É por muitos chamada de a "indústria sem chaminés". Os números e as estatísticas são mesmo impressionantes e salientados por vários autores ente eles: Beni (2000), Lafferty e Fossen (2001), Perales (2002), Imm Ng et al. (2007) e Song e Li (2008).

Especialistas de vários ramos do conhecimento esforçam-se para conceituar turismo, entretanto, a tarefa não é fácil. Segundo Beni (2000) e Theobald (2001), há três tendências para definição de turismo: a econômica, a técnica e a holística. Beni (2000, p. 32) citando a Ansett Airlaines of Austrália (1977), descreve que "turismo refere-se à provisão de transporte, alojamento, recreação, alimentação e serviços relacionados para viajantes domésticos e do exterior. Compreende a viagem para todos os propósitos, desde recreação até negócios”. De acordo com McIntosh (1997) apud Beni (2000, p. 32), "turismo pode ser definido como a ciência, a arte e a atividade de atrair e transportar visitantes, alojá-los e cortesmente satisfazer suas necessidades e desejos”.

Resumindo, Beni (2000, p. 37) afirma que, "em suma, o fato de o turismo encontra-se ligado, praticamente, a quase todos os setores da atividade social humana é a principal causa da grande variedade de conceitos, todos eles válidos enquanto se circunscrevem aos campos em que é estudo". O autor salienta ainda que o "turismo não pode ficar limitado a uma simples definição, pois este fenômeno ocorre em distintos campos de estudo, em que é explicado conforme diferentes correntes de pensamento, e verificado em contextos vários da realidade social".

Tem-se consciência hoje de que o setor turístico é uma indústria capaz de dinamizar a 
economia nacional e local, ao mesmo tempo em que pode contribuir para a coesão e integração econômica e social da nação. No Brasil, o turismo interno desponta como promissora alavanca econômico-social. Um planejamento turístico, com vistas à elaboração de um plano de desenvolvimento turístico, deve resultar do consenso de todos envolvidos no segmento, porém, deve ser articulado e sistematizado por profissionais competentes e especializados (MOURA et al. 2001).

Com as novas tecnologias da informação, enfatizando a Internet que é uma ferramenta que, aproveitada de forma correta no setor de turismo, faz com que se possa ter um resultado positivo como instrumento de marketing, algumas características básicas do mercado de turismo criam um vínculo muito forte com a Internet e o principal deles é que o 'turismo é, basicamente, internacional'. No entanto, mesmo em questões onde a internacionalidade não se aplique, a distância já é motivo suficiente para considerar turismo e Internet mercados convergentes entre si. Segundo Mielenhausen (2000, p. 55), "a Internet é instrumento importante, pois oferece uma espécie de amostra grátis para o consumidor que se encontra à distância”.

No turismo, isso ocorre quando se coloca à venda a imagem dos investimentos turísticos e das satisfações que podem proporcionar. Nesse contexto, a mídia representa um papel fundamental para o turismo (BAUER et al. 2002; BUHALIS e LICATA, 2002). É importante destacar que, os turistas que participaram da pesquisa também destacam a relevância da Internet como ferramenta de comunicação tanto no aspecto tecnológico como estratégico, uma vez que a mesma pode fornecer todas as informações atualizadas aos visitantes em tempo integral, ou seja, ela possibilitará a integração prévia entre os turistas e as informações dos locais que se deseja visitar.

A Internet possui características que a diferencia de maneira relevante das outras formas de mídias tradicionais. Dentre as diversas características, a interatividade permite ao usuário múltipla escolhas para buscar informações de maneiras distintas, faz com que a função de marketing transcenda o paradigma do marketing tradicional que pressupõe consumidores passivos, base desta pesquisa, conforme quadro a seguir. 
Quadro 1 - Características estratégicas da Internet.

\begin{tabular}{|c|l|}
\hline ETAPAS & \multicolumn{1}{c|}{ ATIVIDADES } \\
\hline Ambiente Mercadológico & $\begin{array}{c}\text { - posicionamento de sua empresa na internet; } \\
\text { - identificação de novas oportunidades e ameaças; } \\
\text { - análise da concorrência, suas estratégias, público-alvo etc. }\end{array}$ \\
\hline Conteúdo & $\begin{array}{l}\text { - definir se este conteúdo será fechado, aberto ou pago; } \\
\text { - definir formatos, abrangência, periodicidade e outras } \\
\text { possibilidades. }\end{array}$ \\
\hline Serviços & $\begin{array}{l}\text { - definir que serviços sua empresa irá oferecer no seu website; } \\
\text { - verificar a disponibilidade para implantação dos serviços } \\
\text { (financeiros). }\end{array}$ \\
\hline Publicidade & $\begin{array}{l}\text { - definir que forma sua empresa irá divulgar seu website. Seja } \\
\text { através de publicidade on-line ou off-line; } \\
\text { - definir os formatos que serão adotados; } \\
\text { - Identificar e como medir o retorno desejado. }\end{array}$ \\
\hline Comunicação & $\begin{array}{l}\text { - definir quais as formas de comunicação com o mercado } \\
\text { (prospects, clientes, fornecedores, parceiros, imprensa etc.); } \\
\text { - definir que ações serão utilizadas nesta comunicação (criação de } \\
\text { marca virtual, newsletter - formato, periodicidade, áreas, tópicos) } \\
\text { e o uso do } e \text {-mail marketing nas suas mais variadas formas etc.) }\end{array}$ \\
\hline Interfaces & $\begin{array}{l}\text { - definir que ferramentas serão utilizadas para o desenvolvimento } \\
\text { de seu plano de marketing digital (database marketing, newsletter, } \\
\text { e-mail marketing, medição e análise da audiência, publicidade, } \\
\text { mecanismos de buscas etc.) }\end{array}$ \\
\hline
\end{tabular}

Fonte: adaptado pelos autores.

\section{Metodologia}

A pesquisa presente foi realizada no setor hoteleiro (hotéis e pousadas) da cidade de Maceió $(\mathrm{AL})$, por meio de visitas às empresas, material fornecido pela EMATUR - Empresa Alagoana de Turismo e buscas na Internet verificando-se quais empresas tinham presença ou ausência na Internet, ou seja, quais empresas tinham home page.

Neste trabalho, utilizou-se a pesquisa exploratória-descritiva, em um corte transversal no tempo que visou analisar a utilização de uma forma de tecnologia de comunicação e informação em um determinado momento.

Para a coleta de dados utilizou-se questionários estruturados: um sendo aplicado aos empresários do setor hoteleiro e outro aos turistas (internautas). Com referência aos empresários, foi aplicado tanto para quem tem página na Internet quanto para aqueles que não 
tinham site, com questões que possibilitem identificar o real conhecimento de todos os envolvidos no setor hoteleiro com o uso do marketing na Internet e como eles estão trabalhando com este instrumento estratégico e procurando identificar quais as razões por que não utilizam. As respostas obtidas através dos turistas possibilitaram delimitar um percentual dos turistas que utilizam a Internet para obter informações, deste modo, podendo verificar a utilidade de uma home page como ferramenta competitiva. Ambos participantes empresários e turistas -, analisaram um modelo de site que continha vários serviços e informações para os turistas (33 variáveis). A coleta de dados foi efetuada da seguinte forma:

- Empresários do setor hoteleiro: as entrevistas despenderam 73 dias, entrevistando-se 50 representantes das empresas do setor hoteleiro, que garantiu uma margem de segurança de $95 \%$ e erro amostral de 4,26\%. A amostra respondeu, portanto, cerca de $90,9 \%$ da população. Das 50 empresas pesquisadas, 32 não têm site e, destas, apenas 6 estão conectadas à Internet ${ }^{4}$. - Turistas: foi disponibilizado um questionário on-line que permaneceu durante 38 dias à disposição dos internautas, tempo necessário para que se obtivesse um número de respostas considerada satisfatória da população. Neste período, dos 5.200 e-mails enviados, 393 participantes (internautas) responderam o questionário satisfatoriamente (7,6\% de retorno).

Os participantes que responderam ao questionário atenderam às expectativas da pesquisa, pois o perfil levantado aproxima-se de outras pesquisas realizadas por meio da Internet. É fundamental ressaltar que, esta foi a melhor forma de se atingir o público desejado, como afirma White (2000), enquanto não ideal, este método é talvez a melhor opção atualmente disponível para identificar sub-populações de usuários da Internet.

De acordo com Malhotra (2001), quando o correio (também aplicável ao correio eletrônico) é utilizado para a coleta de dados, as amostras obtidas são não probalísticas, mesmo que os questionários tenham sido postados para uma amostra probabilística, pois ninguém pode garantir que o conjunto dos que se prestaram a responder aos questionários constitui uma amostra probabilística. A decisão de responder ou não aos questionários cabe exclusivamente aos respondentes, que decidirão, em última análise, se farão ou não parte da amostra.

Para o processamento dos dados utilizou-se o software Statistical Package for Social Sciences (SPSS). Quanto as análises estatísticas utilizou-se a distribuição e freqüência e tabulação

\footnotetext{
${ }^{4}$ Cálculo efetuado levando em consideração as 55 empresas que atenderam aos objetivos da pesquisa.
} 
cruzada além Análise Fatorial (técnica multivariada).

Segundo Malhotra (2001), a Análise Fatorial permite ao pesquisador: a) identificar os fatores que explicam as correlações entre um conjunto de variáveis; b) reduzir toda a extensa informação original a um pequeno conjunto de variáveis - os fatores, que representam a combinação linear das variáveis originais, e c) os fatores são independentes entre si, permitindo que este conjunto menor de variáveis não correlacionadas substitua o conjunto original nas análises seguintes a serem realizadas com outras técnicas multivariadas.

A premissa mais importante é a de que existem fatores que dão suporte às variáveis e que as variáveis representam completa e adequadamente esses fatores (AAKER et al. 2001). Os autores destacam que para compreensão da técnica é necessário: i) carga fatorial, medida de correlação entre a função derivada e as medidas originais; ii) score fatorial: é a medida que os objetos analisados assumem na função derivada da análise; iii) o eigenvalue (autovalor), que permite mensurar a contribuição do fator ao modelo constituído pela análise fatorial. Quanto maior o seu valor, maior a sua contribuição; iv) a comunalidade que indica o quanto da variância de uma variável é explicada pelos fatores comuns extraídos na análise fatorial, e v) a matriz fatorial, ou seja, matriz de correlação entre as variáveis originais e os fatores encontrados.

\section{Análise dos Dados e Discussão dos Resultados}

\subsection{Setor hoteleiro de Maceió}

Como o estudo trata do uso estratégico da Internet no setor hoteleiro, levantou-se os custos de montar uma site com características essenciais, ou seja, com informações e serviços que atendam às principais necessidades das pessoas que desejam viajar para um destino turístico. $\mathrm{O}$ modelo de site desenvolvido, no âmbito do presente estudo, apresenta serviços fundamentais para os turistas. Este modelo foi apresentado aos empresários e aos turistas, para que os mesmos opinassem sobre os serviços oferecidos. O modelo de site apresentado disponibilizaria vários serviços, tais como: fotos do hotel ou pousada, fotos do restaurante, quadro de tarifas, roteiro turístico oficial e opcional, promoções on-line, mapa da cidade, fotos das praias, roteiro de compras, entre outras.

O questionário aplicado junto aos empresários do setor hoteleiro, continha questões que foram aplicadas a todos, independentemente de se ter ou não site, como também existiam questões 
exclusivamente para os empresários que tinham site, e questões exclusivamente que foram respondidas pelos empresários que ainda não estavam conectados à Internet.

Verificou-se que, das 18 empresas que tinham sites, os empresários não levaram muito tempo planejando seu ingresso na Internet, como se observa-se na tabela 1, onde verifica-se que $27,8 \%$ declararam que gastaram 30 dias em média para se conectarem e 16,7\% gastaram menos que 30 dias.

Tabela 1 - Tempo de planejamento para a conexão

\begin{tabular}{lcc}
\hline \multicolumn{1}{c}{ Tempo } & Freqüência & \% \\
\hline Menos de 30 dias & 3 & 16,7 \\
30 dias & 5 & 27,8 \\
Entre 30 e 60 dias & 2 & 11,0 \\
Entre 60 e 120 dias & 5 & 27,8 \\
Não informou & 3 & 16,7 \\
\hline \multicolumn{1}{c}{ Total } & 18 & 100,00 \\
\hline \hline
\end{tabular}

Fonte: Dados da pesquisa.

O bom planejamento é fundamental para que um empreendimento tenha sucesso, visto que não se trata simplesmente de colocar uma página na Web para que os clientes acessem, é necessário divulgação e planejamento para conseguir atingir o público-alvo interessado pelo tipo de informação e serviço que a empresa oferece.

Com referência à divulgação do endereço do site da empresa antes de interligar-se à Internet, $27,8 \%$ das empresas utilizou cartão de visita e material impresso e, 22,2\% não fizeram nenhum tipo de publicidade. Mesmo após estabelecer a presença na Internet, 16,7\% das empresas continuam a não fazer publicidade para divulgar a home page e apenas $22,2 \%$ dos entrevistados declararam que continuam a divulgar o endereço da empresa na Internet.

Com referência aos motivos da conexão na Internet, os entrevistados declararam que suas prioridades (tabela 2). 
Tabela 2 - Motivos que levaram a empresa ter presença na Internet

\begin{tabular}{clc}
\hline Ordem & \multicolumn{1}{c}{ Motivo } & $\mathbf{\%}^{5}$ \\
\hline \hline $1^{\mathbf{o}}$ & Perspectivas de aumento de vendas & 37,5 \\
$2^{\mathrm{o}}$ & Acompanhamento da evolução tecnológica & 21,4 \\
$3^{\mathrm{o}}$ & Perspectivas de redução dos custos & 28,6 \\
$4^{\mathrm{o}}$ & Melhoria do atendimento ao cliente & 26,7 \\
$5^{\mathrm{o}}$ & Alcance de novos mercados & 28,6 \\
$6^{\mathrm{o}}$ & Providenciar melhores serviços de pré e pós-vendas & 15,4 \\
$7^{\mathrm{o}}$ & Atingir o mercado internacional & 14,3 \\
\hline \hline
\end{tabular}

Fonte: Dados da pesquisa.

Torna-se de suma importância aos empresários a conscientização sobre o uso da Internet, haja vista que a mesma é uma ferramenta fundamental para providenciar serviços antes e depois das vendas aos clientes. No entanto, esta prioridade aparece em sexto lugar, de acordo com os entrevistados.

Alguns itens foram apresentados aos entrevistados sobre o uso da Internet como instrumento de competitividade e que os mesmos opinassem sobre cada item (tabela 3). Verifica-se que os empresários ainda não estão utilizando a Internet como ferramenta estratégica, pois constata-se que quase a metade dos entrevistados $(43,7 \%)$ não possuem um método formal para medir a efetividade do site na disseminação de informações, apesar de considerar que o principal objetivo do site é disponibilização e informações aos clientes, com índice de 93,3\%. Outro dado que comprova o problema mencionado anteriormente é que $43,7 \%$ não sabem informar se a Internet alcança uma clientela diferente daquela alcançada pelo marketing tradicional.

\footnotetext{
${ }^{5} \mathrm{O}$ percentual refere-se à quantidade de vezes que o motivo foi citado. $\mathrm{O}$ respondente analisava todos os itens e enumerava por ordem de prioridade, indicando o número 1 para o principal motivo, o número 2 para o seguinte $\mathrm{e}$ assim sucessivamente. É importante informar que nem todos os entrevistados opinaram sobre cada afirmação.
} 
Tabela 3 - Uso da Internet como ferramenta estratégica de negócio ${ }^{6}$

\begin{tabular}{|c|c|c|c|c|c|c|}
\hline \multirow[t]{2}{*}{ AFIRMAÇÕES } & \multicolumn{2}{|c|}{ SIM } & \multicolumn{2}{|c|}{ NÃO } & \multicolumn{2}{|c|}{$\begin{array}{l}\text { NÃO } \\
\text { SABE }\end{array}$} \\
\hline & $\mathbf{f}$ & $\%$ & $\mathbf{f}$ & $\%$ & $\mathbf{F}$ & $\%$ \\
\hline $\begin{array}{l}\text { a) O site da empresa alcança uma clientela diferente daquela } \\
\text { através do canal tradicional. }\end{array}$ & 8 & 50,0 & 1 & 6,3 & 7 & 43,7 \\
\hline b) O principal objetivo do site é gerar lucros para empresa. & 13 & 81,3 & 3 & 18,7 & - & - \\
\hline $\begin{array}{l}\text { c) O site da empresa tem sido bem-sucedido na geração de } \\
\text { lucro. }\end{array}$ & 8 & 53,3 & 5 & 33,4 & 2 & 13,3 \\
\hline $\begin{array}{l}\text { d) O principal objetivo do site é providenciar informações sobre } \\
\text { a empresa e serviços. } \\
\text { e) A empresa tem método formal de medir a efetividade do site }\end{array}$ & 14 & 93,3 & 1 & 6,7 & - & - \\
\hline na disseminação de informação. & 8 & 16,0 & 7 & 43,7 & 1 & 6,3 \\
\hline f) A Internet é uma ferramenta estratégica de negócio. & 14 & 93,3 & 1 & 6,7 & - & - \\
\hline $\begin{array}{l}\text { g) Segurança é um importante fator de sucesso do site da } \\
\text { empresa. }\end{array}$ & 12 & 85,8 & 1 & 7,1 & 1 & 7,1 \\
\hline $\begin{array}{l}\text { h) A Internet melhorou a comunicação da empresa com os } \\
\text { clientes. }\end{array}$ & 13 & 86,7 & 2 & 13,3 & - & - \\
\hline i) A Internet reduziu os custos de marketing da empresa. & 9 & 56,3 & 6 & 37,5 & 1 & 6,3 \\
\hline j) A Internet reduziu os custos de comunicação da empresa. & 9 & 60,0 & 6 & 40,0 & - & - \\
\hline k) A Internet trouxe benefícios para a empresa até o momento. & 12 & 80,0 & 3 & 20,0 & - & - \\
\hline 1) A empresa realiza pesquisa de marketing regularmente. & 10 & 66,6 & 4 & 26,7 & 1 & 6,7 \\
\hline
\end{tabular}

FONTE: Dados da pesquisa.

Com referência as empresas que não estão conectadas a rede, algumas questões que foram apresentadas a fim de verificar as principais razões pelas quais ainda não fizeram a conexão com a Internet e suas intenções com relação a esta ferramenta. Na questão que abordou a principal razão pela qual os empresários não utilizam a Internet, constatou-se que a principal é a falta de recursos $(43,6 \%)$ e $12,5 \%$ dos entrevistados declararam que não vale a pena investir. Foi questionado também às empresas que não têm site, quais são os planos relativos ao uso da Internet na empresa. A maioria das empresas pretendem usar a Internet, 31,3\% planejam utilizar após 1 ano, no entanto, observa-se que 21,5\% das empresas não planejam utilizar a Internet.

No tocante aos dados dos empresários, verifica-se que a Internet está sendo utilizada de forma geral como instrumento de segundo plano pelos empresários e que eles não têm conhecimento de todas as potencialidades da ferramenta e não estão despendendo nem tempo e nem recursos financeiros no uso da Internet como ferramenta estratégica para o e-commerce. $\mathrm{O}$ uso da Internet é uma ferramenta fundamental para as empresas e principalmente para as empresas do setor hoteleiro que pretendem atingir mercados internacionais, utilizando-se de estratégias adequadas.

\footnotetext{
${ }^{6}$ Nem todos os entrevistados responderam todas as afirmações.
} 


\subsection{Perfil e perspectivas dos turistas}

De forma simplificada, apresenta-se o perfil dos respondentes da pesquisa realizada através do questionário on-line, denominado neste estudo como turista, haja vista que estas pessoas, na sua maioria, usam a Internet para obter informações sobre turismo. É importante ressaltar que o perfil levantado, apresenta o mesmo comportamento de outras pesquisas utilizando como meio de pesquisa a Internet. Os internautas típicos são homens, mas a participação feminina vem aumentando, conforme dados do IBOPE/NetRatings (2007). A faixa etária encontrada se concentra entre 20 a 30 anos (44,3\%). Quanto ao estado civil, $60,6 \%$ dos participantes são solteiros. A maioria dos respondentes possuem grau de instrução elevado: superior incompleto $(32,3 \%)$ e superior completo $(27,2 \%)$. A maioria possui casa própria paga $(66,2 \%)$, com renda familiar mensal acima de 21 salários mínimos (56\%). A principal ocupação dos participantes identificada é bastante diversificada, com destaque para estudantes $(29,4 \%)$, seguido por profissionais liberais (14,6\%) e empresários (13,2\%) e demais profissionais, como: professores, consultores, engenheiros, vendedores etc.

Com referência ao uso da Internet pelos respondentes, verifica-se que a maioria dos internautas possui experiência na $W e b$, visto que 43,8\% deles utilizam a Internet há mais de 3 anos e o uso da Internet faz parte do cotidiano dos respondentes (72,8\% são os heavy users, ou seja, conectam-se todos os dias). O principal local de acesso a Internet é a sua própria residência $(50,9 \%)$, seguido no trabalho $(41,7 \%)$. O principal motivo de acesso é o envio e recebimento de e-mails $(50,4 \%)$.

As compras on-line são consideradas inseguras pelos participantes e 52,9\% afirmaram que nunca compraram através da Internet. Entretanto, verifica-se um percentual favorável, 47,1\% que já compraram via Internet. Dos usuários que declararam que nunca compraram através da Internet, 52,5\% declararam que o principal motivo é a falta de segurança.

Albertin (2007) argumenta que muitos especialistas consideram o tema‘segurança na rede' mais uma questão de percepção do que realidade, visto que existe desconfiança de muitos clientes com relação à transmissão de dados confidenciais, como o número do cartão de crédito. Tal desconfiança não é verificada quando da utilização do mesmo cartão em estabelecimentos comerciais, o que confirma que a percepção é um fator importante com relação ao tema 'segurança'.

Com relação aos respondentes que declararam que ainda não compraram através da Internet, $71,7 \%$ afirmaram que compraria. A maioria dos usuários possui cartão de crédito 
internacional (57,5\%). Um dado importante identificado foi que apesar da falta de segurança no uso do cartão de crédito na Internet, $47,8 \%$ dos respondentes afirmaram que pagariam utilizando o cartão de crédito, e a justificativa para isso é que a Internet traz comodidade e conveniência.

A maioria dos respondentes $(67,1 \%)$ usa a Internet para obter informações sobre turismo. Tratando-se do setor hoteleiro, pode-se dizer que ela aumenta a segurança, pois o cliente pode visualizar o meio de hospedagem como apartamentos, restaurantes etc. No passado, o cliente comprava um pacote turístico sem saber como era o meio de hospedagem e quando chegavam ao destino, alguns tinham desagradáveis surpresas. A Internet soluciona, pelos menos parcialmente, este tipo de problema.

No entanto, é importante ressaltar que das pessoas que procuram informações turísticas através da Internet, 30,2\% não ficaram satisfeitos com as informações obtidas. Dentre os insatisfeitos, 35,4\% afirmaram que a demora na resposta do e-mail causou maior insatisfação e, segundo $22,8 \%$ dos respondentes foi devido ao excesso de publicidade no site, ao invés das informações necessárias.

A forma escolhida para uma reserva de um hotel ou pousada encontrados através da Internet, foi através de formulário on-line (56\%) e 21,4\% através de um telefone gratuito.

\subsection{Perspectivas dos empresários do setor hoteleiro}

De acordo com Malhotra (2000), Aaker et al. (2001) e Zikmund (2006), pode-se definir "análise fatorial" como uma técnica estatística elaborada para dividir as muitas perguntas num teste em tão poucos grupos coerentes quanto possíveis. Em outras palavras, em vez de explicar de que modo os participantes responderam a cada questão individual, o fator de análise tenta explicar os padrões de respostas dos participantes em termos de um número menor de fatores hipotéticos. Zikmund (2006) afirma que, por causa da não confiabilidade e outros erros de medida, as cargas fatoriais (factor loadings) de uma questão geralmente estará bem abaixo de 1, pois as cargas fatoriais, com os coeficientes de correlação, podem variar de 1 a +1 . Segundo o autor, uma carga fatorial de $+0,70$ é considerado muito alto e muitos pesquisadores se contentam caso uma questão tenha uma carga fatorial acima de $+0,30$.

É importante ressaltar que, os itens estudados referem-se ao modelo de site proposto e assim poderá verificar as correlações entre as variáveis apresentadas. Com o objetivo de avaliar o grau de importância dos atributos considerados necessários no modelo, utilizou-se da escala do tipo Likert de 5 pontos (discordo totalmente a concordo totalmente) assumindo-a como 
intervalar. De acordo com o estabelecido, na análise fatorial foram mantidos somente as variáveis com cargas fatoriais maiores que 0,50 para os fatores encontrados (tabela 4).

Tabela 4 - Análise fatorial do modelo (empresários do setor hoteleiro)

\begin{tabular}{|c|c|c|c|}
\hline FATORES & \begin{tabular}{|c|} 
Carga \\
Fatorial
\end{tabular} & $\begin{array}{c}\text { Variância } \\
\text { Explicada (\%) }\end{array}$ & $\begin{array}{l}\text { Alp } \\
\text { ha } \\
(\alpha)\end{array}$ \\
\hline $\begin{array}{l}\text { Fator 1: Comunicação e informação } \\
\text { Comentários sobre o folclore e comidas típicas } \\
\text { Bares e boates da cidade } \\
\text { Restaurantes da cidade } \\
\text { Telefones importantes da cidade } \\
\text { Roteiro de compras na cidade (ex.: artesanatos) } \\
\text { Mapa da cidade }\end{array}$ & $\begin{array}{l}0,879 \\
0,869 \\
0,828 \\
0,709 \\
0,704 \\
0,630 \\
\end{array}$ & 25,1 & $\mathbf{0 , 8 7}$ \\
\hline $\begin{array}{l}\text { Fator 2: Prestação de serviços } \\
\text { Horário de chegada e saída de ônibus para as capitais do } \\
\text { Brasil } \\
\text { Horário de chegada e saída de aviões para as capitais do } \\
\text { Brasil } \\
\text { Previsão do tempo na cidade } \\
\text { Roteiro turístico opcional } \\
\text { Roteiro turístico oficial } \\
e \text {-mail }\end{array}$ & $\begin{array}{l}0,831 \\
0,793 \\
0,753 \\
0,715 \\
0,682 \\
0,580 \\
\end{array}$ & 12,9 & $\mathbf{0 , 8 1}$ \\
\hline $\begin{array}{l}\text { Fator 3: Aspectos de design de interface } \\
\text { FAQs (Frequently Asked Questions) } \\
\text { Formulário para feedback }\end{array}$ & $\begin{array}{l}0,818 \\
0,750 \\
\end{array}$ & & \\
\hline $\begin{array}{l}\text { Search engine do site (busca do site) } \\
\text { What's new? Ou Jornal da empresa } \\
\text { Fórum de opiniões } \\
\text { Opções de língua } \\
\text { Telefone número } 0800 \\
\text { Conversor de moedas }\end{array}$ & $\begin{array}{l}0,737 \\
0,735 \\
0,637 \\
0,595 \\
0,574 \\
0,564 \\
\end{array}$ & 9,8 & 0,85 \\
\hline $\begin{array}{l}\text { Fator 4: Aspectos de marketing e e-commerce } \\
\text { Promoções on-line } \\
\text { Fotos dos apartamentos, quartos... } \\
\text { Opções de pagamento } \\
\text { Reserva on-line } \\
\text { Distância entre o hotel e as praias } \\
\text { Foto da fachada do hotel/pousada }\end{array}$ & $\begin{array}{l}0,653 \\
0,648 \\
0,624 \\
0,612 \\
0,612 \\
0,587 \\
\end{array}$ & 6,7 & 0,73 \\
\hline $\begin{array}{l}\text { Fator 5: Comunicação visual } \\
\text { Fotos da cidade } \\
\text { Fotos dos pratos do restaurante do hotel } \\
\text { Fotos das praias } \\
\text { Foto do restaurante }\end{array}$ & $\begin{array}{l}0,786 \\
0,683 \\
0,673 \\
0,634 \\
\end{array}$ & 6,1 & 0,74 \\
\hline Variância T & xplicada & 60,6 & \\
\hline
\end{tabular}

Fonte: Dados da pesquisa.

Observa-se na tabela 4 que os valores do fator 1 têm elevada consistência interna, com 
variância explicada de 25,1\%. Testada a precisão de alpha de Cronbach de seus 6 itens, encontrou-se o coeficiente de 0,87 considerado altamente satisfatório. Este fator foi aqui denominado de "comunicação e informação", que um site de hotel deveria oferecer aos seus visitantes. Verifica-se que os empresários tiveram respostas correlacionadas referentes a estes itens, demonstrando a importância da disponibilização de comunicação e informação entre a empresa e os usuários.

O segundo fator explicou $12,9 \%$ da variância total. Constatou-se existir, como elo entre as variáveis deste fator, a necessidade de "prestação de serviços". Observa-se que as cargas fatoriais são satisfatórias, demonstrando que os empresários reconhecem a necessidade de prestar serviços aos seus clientes, não apenas na empresa, mas também sobre a cidade, meios de locomoção e principalmente sobre os tipos de roteiros turísticos que o turista pode utilizar para melhor aproveitar sua estadia na cidade. Sabe-se que, a prestação de serviço é tudo aquilo que a empresa faz para facilitar a vida dos clientes. O coeficiente de precisão alpha de Cronbach para este fator é de 0,81 , que também é considerado altamente satisfatório.

O fator 3 explicou 9,8\% da variância total e refere-se aos "aspectos de design de interface", ou seja, às formas de comunicação entre a empresa e os usuários. Verifica-se que as cargas fatoriais foram satisfatórias, evidenciando a necessidade destes serviços. Testada a precisão de alpha de Cronbach de seus 8 itens, encontrou-se o coeficiente de 0,85 considerado altamente satisfatório.

O fator 4 representou a percepção dos empresários com referência ao uso da Internet para o comércio eletrônico e como ferramenta de marketing. Os itens deste fator apesar de apresentar cargas fatoriais menores, é de suma importância para a empresa que queira desenvolver e realizar transações da Internet. Quando a empresa utiliza os itens que compõem o fator 4, como promoções on-line, reserva on-line etc., ela consegue atingir as ferramentas que se enquadram em cinco categorias bem amplas: propaganda, promoções de vendas, relações públicas, força de vendas e marketing direto. $\mathrm{O}$ fator 4 foi aqui denominado de "aspectos de marketing e e-commerce", explicando 6,7\% da variância observada, com coeficiente de alpha de Cronbach de 0,73 de precisão. O coeficiente é considerado satisfatório.

O quinto fator denominado de "comunicação visual", explicou 6,1\% da variância total, com alpha de Cronbach satisfatório de 0,74. Este fator demonstra que os empresários do setor 
hoteleiro consideram importante a disponibilização de imagens da cidade, das praias etc., a fim de aumentar a comodidade do turista, pois assim o mesmo saberá identificar que ponto turístico é interessante ser visitado.

Verifica-se que as informações e serviços a serem disponibilizados no site de hotel foram considerados importantes, conforme demonstra a análise fatorial, apresentando correlações entre as respostas dos empresários do setor hoteleiro. Os 5 fatores extraídos apresentaram um alpha de precisão de 0,88, considerado altamente satisfatório.

A análise fatorial demonstrou que os empresários reconhecem a importância do uso da Internet no setor hoteleiro para o e-commerce, no entanto, estes empresários ainda não estão dando toda ênfase a Internet como ferramenta de marketing e como estratégia de competitividade, a partir do momento que ainda não disponibilizam tais informações e serviços, e também não estão dispostos a investir o total de recursos financeiros necessários para a construção do site apresentado no modelo, ou seja, prestar serviços que atendam as expectativas dos consumidores conscientes e bem informados.

\section{Considerações Finais}

Com os resultados obtidos na presente pesquisa foi possível concluir que os empresários do setor hoteleiro de Maceió (AL) ainda não estão utilizando a Internet em toda sua potencialidade. Aqueles empresários que ainda não estão com home page na Internet, alegam a falta de recursos financeiros para a conexão, mas também observou-se a falta de recursos humanos experientes nas empresas que já estão conectadas.

As empresas do setor hoteleiro utilizam a Internet, muitas vezes, de forma semelhante às mídias tradicionais, encontrando-se ainda num estágio inicial em termos da exploração do seu potencial. As empresas passam por estágios de utilização de tecnologia interativa até utilizá-la em sua plenitude. À medida que cresce o entendimento da tecnologia da informação e essa nova cultura permeia a organização, há uma evolução natural para o estágio posterior, ou seja, perpassa um estágio de prestação de informação para um estágio de transação eletrônica.

É importante relembrar que, estudos demonstram que o número de usuários da Internet cresce a cada dia. Estas pessoas usarão a Internet para solucionar seus problemas, visto que, a internet funciona 24 horas por dia e 7 dias por semana, trazendo comodidade e conveniência para seus usuários. Torna-se importante ressaltar ainda que, como demonstrou a pesquisa 
realizada junto aos turistas para este estudo, apesar de algumas falhas da Internet (principalmente quanto a segurança), as pessoas já estão comprando e comprarão cada vez mais através da Internet e esta é uma informação fundamental para qualquer empresa que deseje sobreviver numa era tão competitiva.

Para consecução da pesquisa, surgiu alguns imprevistos, como o tamanho da amostra, apesar de ser bem representativa da população em estudo, nem todas as empresas estão conectadas à Internet. Outro dado relevante, foi que mesmo os empresários estando com suas empresas conectadas, nem todos possuem know how para gerir o uso da Internet como instrumento de marketing e como ferramenta de competitividade. Destarte, pode-se afirmar que, a Internet é um instrumento estratégico para empresas melhorar sua comunicação com os clientes atuais e conquistar novos clientes com uma abordagem efetiva de relacionamento e interatividade em tempo real no ambiente on-line.

Faz-se uma ressalva aqui, devido se tratar de locus turístico onde foi realizada a pesquisa, e que todas as potencialidades da Internet devem ser utilizadas para desenvolver estratégias mercadológicas para o segmento turístico, não somente para Maceió, mas para todo estado de Alagoas, bem como todas as regiões com potencial turístico no Brasil, que são subutilizadas. No entanto, ressalta-se também que, a Internet permite desenvolver um programa de turismo sustentável, com uso da Internet para informar aos futuros visitantes ações ambientalmente responsáveis.

\section{Referências}

AAKER, D. A. 2001. et al. Pesquisa de marketing. São Paulo: Atlas.

ABREU, N. R. 2006. Comunidades virtuais como fonte de informações para estratégias mercadológicas: o caso do setor de turismo. 249 p. Tese (Doutorado em Administração) Universidade Federal de Lavras, Lavras, MG.

ALBERTIN, L. A. 2007. Comércio eletrônico: modelo, aspectos e contribuições de sua aplicação. 5. ed. São Paulo: Atlas.

ARZUAGA, G. R. . Marketing en internet. Disponível em: http://www.netgocios.com/default2.htm. Acesso em 15 ago. 1999.

BAUER, H. H. 2002. et al. Building customer relations over the internet. Industrial Marketing Management, n. 31, p. 155-163.

BENI, M. C. 2000. Análise estrutural do turismo. 3. ed. São Paulo: Editora SENAC.

BUHALIS, D.; LICATA, M. C. 2002. The future eTourism intermediaries. Tourism Management, $\mathrm{n}$. 23, p. 207-220.

CHENG, T. C. E. 2006. et al. Adoption of internet banking: an empirical study in Hong Kong. 
Decision Support Systems, v. 42, n. 3, p. 1558-1572, dec.

IBOPE/NetRatings. 2007. Resumo da audiência de internet domiciliar no Brasil e perfil do internauta brasileiro. jul. CD-ROM.

IMM NG, S. 2007. et al. Tourists' intention to visit a country: the impact of cultural distance. Tourism Management, v. 8, n. 6, p. 1497-1506, dec.

KOTLER, P.; ARMSTRONG, G. Princípios de marketing. Rio de Janeiro: Prentice-Hall, 1993.

LAFFERTY, G.; FOSSEN, A. V. 2001. Integrating the tourism industry: problems and strategies. Tourism Management, n. 22, p. 11-19.

MALHOTRA, N. K. 2001. Pesquisa de marketing. 3. ed. Porto Alegre: Bookman.

MATTAR, F. N. 1998. Pesquisa de marketing: execução e análise. 2. ed. São Paulo: Atlas, v. 2.

MIELENHAUSEN, U. 2000. Gestão de mix promocional para agências de viagens e turismo. In: LAGE, B. H. G.; MILONE, P. C. (Orgs.). Turismo: teoria e prática. São Paulo: Atlas.

MOURA, E. 2001. et al. Desafios da administração no desenvolvimento turístico. Revista Brasileira de Administração, Brasília: n. 33, jun.

PERALES, R. M. Y. 2002. Rural tourism in Spain. Annals of Tourism Research, v. 29, n. 4, p. 11011110.

SILVA, J. A. R.; OLIVEIRA, L. C. V. de. 1997. O marketing na Internet.BR: uma avaliação da presença empresarial na World Wide Web. In: XXI ENANPAD - ENCONTRO NACIONAL DOS PROGRAMAS DE PÓS-GRADUAÇÃO EM ADMINISTRAÇÃO. Anais eletrônicos. Rio das Pedras-RJ: ANPAD.

SONG, H.; LI G. 2008. Tourism demand modelling and forecasting: a review of recent research. Tourism Management, v. 29, n. 2, p. 203-220, april.

SWINGLEHURST, E. 2001. Contato direto: os efeitos do turismo nas sociedades do passado e nas atuais. In: THEOBALD, W. F. (Org.). Turismo global. São Paulo: Editora SENAC.

THEOBALD, W. E. 2001. Significado, âmbito e dimensão do turismo. In: Turismo global. São Paulo: Editora SENAC.

URRY, J. 1996. O olhar do turista. São Paulo: Studio Nobel: SESC.

WHITE, G. K. S/D. An on-line survey of food and beverage consumers on the internet: an evaluation of the survey methodology. Disponível em: http://marketing-bulletin.massey.ac.nz. Acesso em: 24 jan. 2000 .

ZIMUND, W. G. 2006. Princípios da pesquisa de marketing. São Paulo: Pioneira Thomson Learning.

\section{Recebido em: 28/07/2008}

Aprovado em: 22/09/2008 